\title{
Uncertainty analysis of Archie's parameters determination techniques in carbonate reservoirs
}

\author{
G. M. Hamada • A. A. Almajed · T. M. Okasha • \\ A. A. Algathe
}

Received: 26 September 2010/ Accepted: 29 October 2012/Published online: 18 November 2012

(C) The Author(s) 2012. This article is published with open access at Springerlink.com

\begin{abstract}
Reservoir evaluation is one of the critical tasks of any reservoir exploration and field development plan. Water saturation calculated from open-hole resistivity measurements is a primary input to hydrocarbon reserves evaluation. Archie's equation is the water saturation model for the determination of water saturation. Application of Archie equation in carbonate reservoir is not easy due to high dependency of its parameters on carbonate characteristics. Determination techniques of Archie's parameters are relatively well known and validated for sandstone reservoirs, while carbonates are heterogeneous and a correct estimation of Archie' parameter is important in their evaluation. In the case of carbonate rocks, there are considerable variations in texture and pore type, so, Archie's parameters become more sensitive to pores pattern distribution, lithofacies properties and wettability. Uncertainty in Archie's parameters will lead to non-acceptable errors in the water saturation values. Uncertainty analysis has shown that in calculating water saturation and initial oil in place, the Archie's parameters $(a, m, n)$ have the largest influence and $R_{\mathrm{t}}$ and $R_{\mathrm{w}}$ are the least important. The main objective of this study was to measure Archie's parameters on 29 natural carbonate core plugs at reservoir conditions, using live oil,
\end{abstract}

G. M. Hamada ( $\square)$

United Arab Emirates University, Al Ain, UAE

e-mail: ghamada@uaeu.ac.ae

A. A. Almajed

King Fahd University of Petroleum and Minerals,

Dhahran, Saudi Arabia

T. M. Okasha

Aramco Co., Dhahran, Saudi Arabia

A. A. Algathe

Hadhramout University, Mukalla, Yemen these core samples were taken from three wells. For this purpose, three techniques were implemented to determine Archie's parameters; conventional technique, core Archie's parameters estimate technique and three-dimensional technique. Water saturation profiles were generated using the different Archie parameters determined by the three techniques. These profiles have shown a significant difference in water saturation values and such difference could be mainly attributed to the uncertainty level for the calculated Archie parameters. These results highlight the importance of having accurate core analysis's measurements performed on core samples that yield representative $a, m$ and $n$ values that highly influence the water saturation values.

Keywords Archie's parameters - Water saturation · Uncertainty · Carbonate reservoir and determination . Techniques

$\begin{array}{ll}\text { List of symbols } \\ a & \text { Tortuosity factor } \\ m & \text { Cementation factor } \\ n & \text { Saturation exponent } \\ S_{\mathrm{w}} & \text { Water saturation, fraction } \\ R_{\mathrm{t}} & \text { Resistivity of rock, } \Omega \mathrm{m} \\ R_{\mathrm{w}} & \text { Resistivity of brine, } \Omega \mathrm{m} \\ R_{\mathrm{o}} & \text { Resistivity of rock with } S_{\mathrm{w}}=1.0, \Omega \mathrm{m} \\ I_{\mathrm{r}} & \text { Resistivity index } \\ F & \text { Formation resistivity factor } \\ \varphi & \text { Formation porosity, fraction } \\ E_{\mathrm{a}} & \text { Average absolute percent relative error } \\ E_{\mathrm{min}} / E_{\mathrm{max}} & \text { Minimum/maximum absolute error } \\ S & \text { Standard deviation } \\ E_{\mathrm{rms}} & \text { The root mean square error } \\ R & \text { The correlation coefficient }\end{array}$

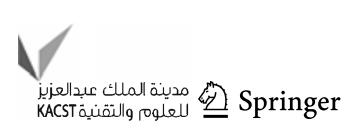




\section{Introduction}

Carbonate reservoirs represent about $20 \%$ of the world's sedimentary rocks and contain more than $40 \%$ of the world's hydrocarbon reserves. Carbonates are formed in special environments and they are biochemical in origin. Carbonates heterogeneity is the result of subsequent physical and chemical reorganization processes, such as compaction, solution, dolomitization and cementation. This heterogeneity complicates the task of reservoir description, where reservoir properties tend to vary as a function of spatial locations both in vertical and areal direction. Carbonates are characterized by different types of porosity and other complex pore size distributions, which result in wide permeability variations for the same porosity, making it difficult to predict their producibility. The key link in understanding carbonate reservoirs is recognizing the critical link between geological heterogeneity and reservoir quality and performance (Serag et al. 2010; Chilingarian et al. 1992; Jodry 1992; Wardlaw 1996).

Carbonates pore geometry and wettability mainly influences the cementation exponent $(m)$ and saturation exponent $(n)$ of Archie's equation. Cementation exponent varies constantly which has a significant effect on the computation of water saturation using resistivity logs. Carbonates have mixed wettability. Saturation exponent (n) which is an important parameter in log analysis depends on the wettability. Alteration of wettability in the process of coring, transportation, and storage is another issue which needs careful consideration. A critical petrophysics task is to match data acquisition to reservoir complexity. This task is comparatively straightforward for Archie reservoirs, while for non-Archie reservoirs, it is more difficult to achieve because data-driven perception of reservoir complexity often are too simplistic (Morgan and Pirson 1964; Fluery 1998; Han et al. 2007; Hamid et al. 2011; Worthington 2011).

Problematic reservoirs present a petrophysical challenge that can be met only by departing from classical methodology. Determination of recoverable hydrocarbons or at least of hydrocarbon in place is the primary goal of a designed formation evaluation program. In routine formation evaluation, Archie's parameters $a, m$ and $n$ are held constants with default saturation exponent $n=2$ (Archie 1942). However, the saturation exponent $n$ varies greatly from the common value of 2 in strongly water wet reservoir rocks to more than 20 in strongly oil wet reservoir rocks and sometimes the resistivity index (RI) curves become nonlinear in log-log scale. Wettability effects become important in the case of partial water saturation reservoir pore spaces. Petroleum literature presents an extensive review of the results determining Archie's parameters and also water saturation computation processes. Accuracy water saturation values rely on the uncertainty of Archie's parameters used either in Archie saturation equation in clean formation or in a shaly sand water saturation model in shaly formation (Archie 1942; Dewhite 1950; Atkins and Smits 1961; Simandoux 1963; Waxman and Smits 1968; Clavier et al. 1984; Sen 1997; Kennedy et al. 2001; Bori 1987; Al-Ruwaiili and Alwaheed 2004; Dernaika et al. 2007). This paper presents the results of the application of three techniques to determine Archie's parameters: (1) three-dimensional regression (3D) technique, which is based on the analytical expression of three dimension plot of $R_{\mathrm{t}} / R_{\mathrm{w}}$ versus $S_{\mathrm{w}}$ and $\phi,(2)$ core Archie's parameters estimate (CAPE) and (3) conventional technique. Uncertainty analysis was done for each technique and also for the relevant impact on the water saturation values using Archie' equation.

\section{Core samples selection and preparation}

A total of 29 plug samples (15 in. $\times 2.5$ in.) were received from three wells, 12 core samples are from well A, 9 core samples from well $\mathrm{B}$, and 8 core samples from well $\mathrm{C}$. These core samples represent different ranges of porosity and permeability and are basically limestone and dolomite. Some of these cores have vugs shown in the photograph of six core samples (Fig. 1). These vugs seem to cause the heterogeneity in the petrophysical properties of the core plugs. The core plug samples were trimmed to ensure plane and parallel surfaces at both ends. Rough edges in the core plugs were smoothened using gypsum. The core samples were then cleaned with toluene for $12-16 \mathrm{~h}$ to remove residual oil and then cleaned for $8-10 \mathrm{~h}$ in methanol alcohol to remove salt from the pores. The core samples were dried in an oven for $24 \mathrm{~h}$ under vacuum and the dry weight of the core samples were recorded. The dried core samples were vacuumed in a cylindrical cell for about $4 \mathrm{~h}$. After sufficient vacuuming, the samples were saturated with brine. Then, a pressure was of 2,000 psi was applied to ensure complete saturation of small pores. The weight of the saturated core samples is recorded. The core samples were then loaded to electrical cart cells or kept preserved inside a vacuum cylinder waiting electrical testing.

\section{Electrical measurements}

A total of 29 carbonate core samples were tested for electrical properties. Two- and four-pole resistivities, temperature, confining pressure, pore pressure, and brine displacement were monitored continuously and recorded by a computer attached to the system. Electrical measurements were taken continuously until resistivity and desaturation equilibriums were reached at each step. 
Fig. 1 Plug samples drilled from Carbonate Arab-D reservoir in well $\mathrm{A}$
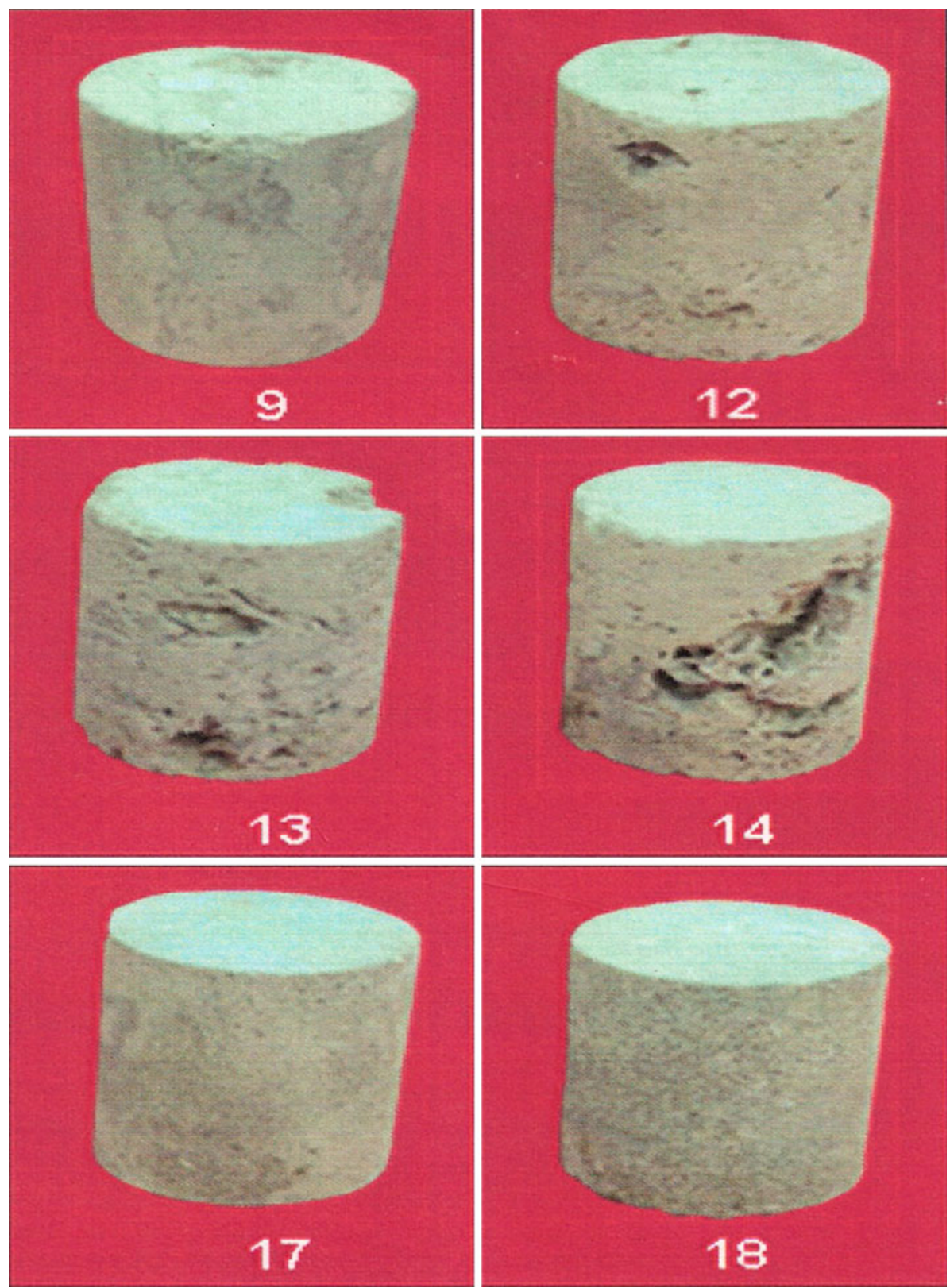

All resistivity measurements were corrected for a reservoir temperature of $80{ }^{\circ} \mathrm{C}$ during data processing. After temperature equilibrium, the confining pressure was raised to 2,500 psi and the brine expelled from each sample was measured. After initial electrical measurements, desaturation was performed gradually from 0 to $120 \mathrm{psi}$ pore pressure. Although four-pole resistivities were used for determining the electrical parameters, two-pole resistivities were also recorded for monitoring the contact problems that might have occurred. The test cell cart contains six test cells (Fig. 2) in which core samples were tested for electrical resistivity properties. Five of these test cells have a $3.5 \mathrm{in}$. inside diameter for testing core samples up to $1.5 \mathrm{in}$. in diameter.

\section{Calculation of Archie's parameters}

Carbonates reservoirs are classified based on their lithology, texture and structure. Archie formula is not easy to be applied to those reservoirs because Archie's parameters are functions of the changes in pore geometry, wettability, tortuosity of the pores, formation pressure and clay content. Carbonate pore geometry and wettability exercise great influence on the cementation exponent $(m)$ and saturation exponent $(n)$ of Archie's formula. Pore geometry can be examined in laboratory by magnetic resonance imaging (MRI) technique with different frequencies or by mercury injection test. Mercury injection test was conducted on the 29 core samples to determine the pore throat size

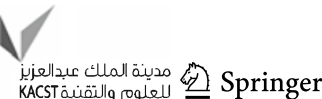


Fig. 2 Electrical resistivity test system



distributions to identify their pores size distributions. Figure 3 shows mercury pressure curves and pore size distribution of four samples; samples 5 and 12 are both foraminiferal grainstone represented by similar mercury injection curves and pore throat size histograms. Asymmetric pore throat size histogram is indicative of bimodality due to microporosity. Slightly carbonate mud bearing packstones were observed in samples 20 and 24. At this stage, the core samples are well described by thin section analysis and mercury injection test interpretation. Examined core plugs were mostly heterogeneous dolomite and limestone with different degree of lithification.

An exact computation of water saturation using Archie's formula is based on an accurate values of Archie's parameters $a, m$ and $n$. For each core sample, the electrical resistivity $R_{\mathrm{o}}$, at $100 \%$ water saturation and $R_{\mathrm{t}}$ at different water saturation percentages were measured at room temperature. The resistivity of simulated brine was prepared to water resistivity $0.2 \Omega \mathrm{m}$. This ambient temperature water resistivity value corresponds to formation water resistivity $0.09 \Omega \mathrm{m}$ at reservoir temperature.

\section{Conventional determination of $a, m$ and $n$}

Archie 1942 proposed an empirical relationship between rock resistivity, $R_{\mathrm{t}}$, with its porosity, $\phi$ and water saturation $S_{\mathrm{w}}$

$S_{\mathrm{w}}^{n}=a R_{\mathrm{w}} / \phi^{m} R_{\mathrm{t}}=R_{\mathrm{o}} / R_{\mathrm{t}}=1 / I_{\mathrm{r}}$.

Conventional determination of $n$

The classical process to determine saturation exponent is based on Eq. 1. This equation is rewritten as: $\log I_{\mathrm{r}}=-n \log S_{\mathrm{w}}$

Logarithmic plot of $I_{\mathrm{r}}$ versus $S_{\mathrm{w}}$ gives a straight line with a negative slope $n$. Figure 4 illustrates the saturation exponent values for the 29 core samples.

Conventional determination of $a$ and $m$

The conventional determination of $a$ and $m$ is based on the following equation:

$\log F=\log a-m \log \phi$

A plot of $\log F$ versus $\log \phi$ is used to determine $a$ and $m$ for the core samples. Cementation factor $m$, is determined from the slope of the least square fit straight line of the plotted points, while tortuosity factor is given from the intercept of the line where $\phi=1$. Note that in this plot only points of $S_{\mathrm{w}}=1.0$ are used. Figure 5 shows formation resistivity versus porosity for core samples; average $m$ equal to 1.87 and the coefficient $(a)$ is equal to 1.12. It is obvious that the conventional technique treats the determination of $n$ as a separate problem from $a$ and $m$. This separated calculation of the two parameters ( $a$, $m$ ) is not physically correct, thereby, it induces an error in the value of water saturation using Eq. 1.

\section{Core Archie-parameter estimation}

Maute et al. (1992) presented a data analysis approach to determine Archie's parameters $m, n$ and optionally $a$ from standard resistivity measurements on core samples. The analysis method, CAPE determines $m$ and $n$ and optionally a by minimizing the error between computed water and 

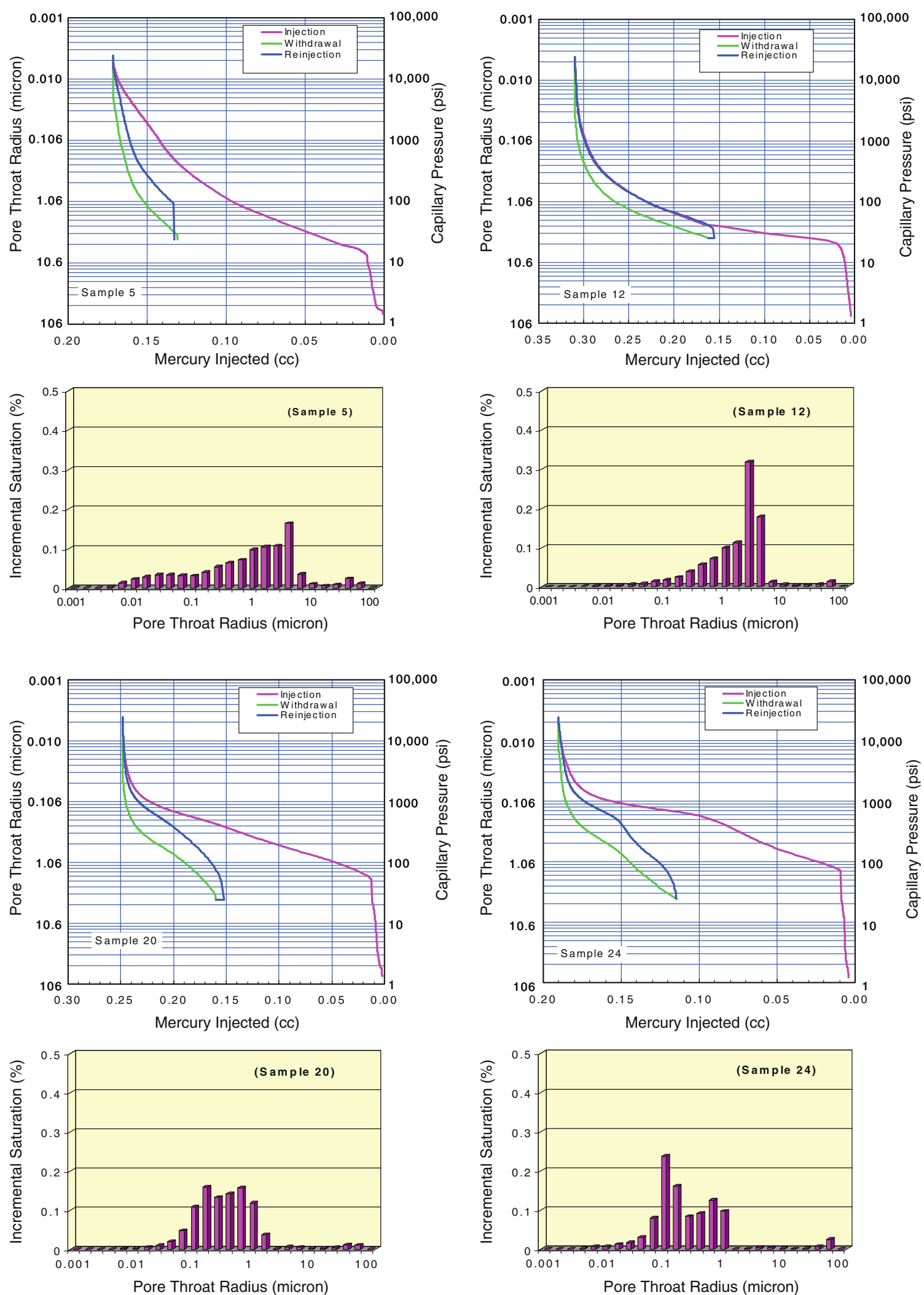

Fig. 3 Mercury capillary pressure curves and pore throat size histograms of samples 5, 12, 20 and 24 
Fig. 4 Resistivity versus water saturation (conventional method)

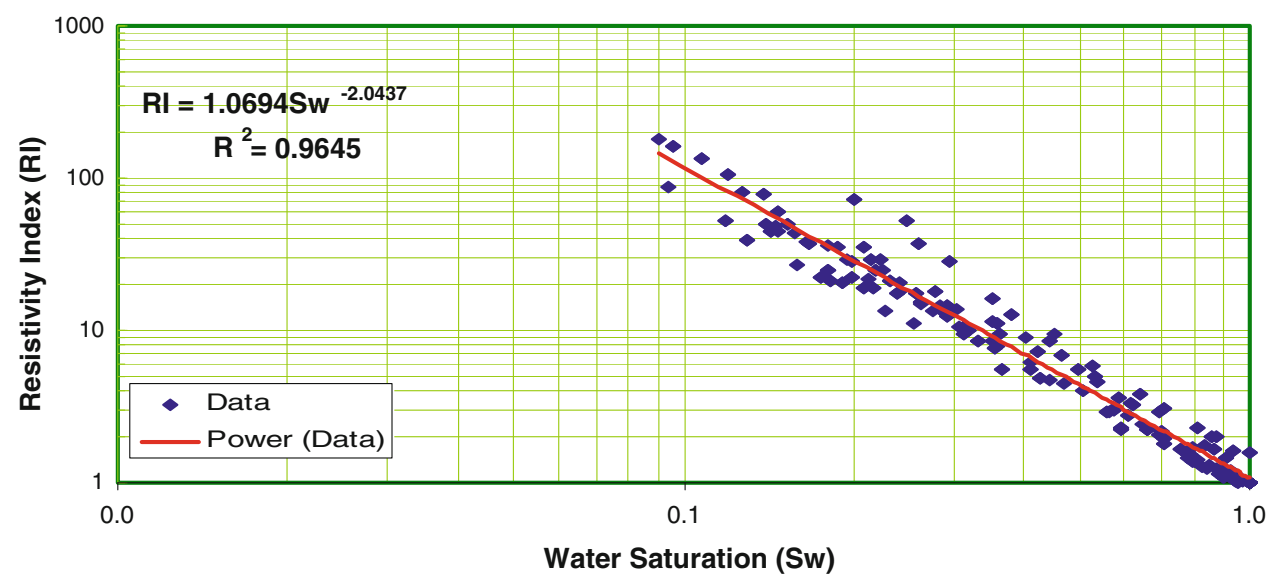

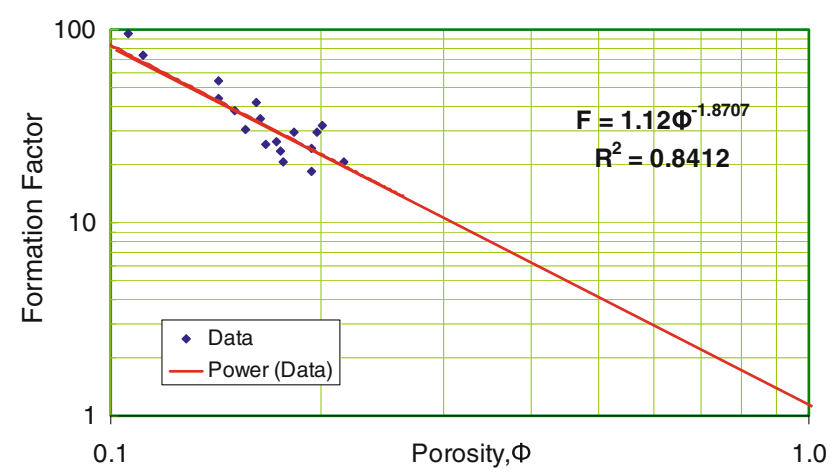

Fig. 5 Formation factor versus porosity (conventional method)

measured water saturations. The mean square saturation error $\varepsilon$, is given by:

$\varepsilon=\sum_{j} \sum_{i}\left[S_{\mathrm{w}_{i j}}-\left(a R_{\mathrm{w}_{i j}} / \phi \mathrm{i}^{m} R_{\mathrm{t}_{i j}}\right)^{1 / n}\right]^{2}$

where $j=$ core index, $i=$ index for each of the core $j$ measurements, $S_{\mathrm{w}_{i j}}=i$ th laboratory measured water saturation for core $j$ (fraction), $R_{\mathrm{t}_{i j}}=i$ th laboratory measured resistivity for core $j, \Omega \mathrm{m}$, and $\phi j=$ core $j$ porosity (fraction). Equation 4 calculates the minimum error between measured core water saturation and computed water saturation by Archie's formula, by adjusting $m, n$ and optionally $a$ in the equation.

\section{Three-dimensional regressions}

Hamada et al. (2002) proposed 3D technique to determine Archie's parameters $a, m$ and $n$ using standard resistivity measurements on core samples.

Methodology

The basis of the 3D technique is to consider viewing $S_{\mathrm{w}}$ in Archie's formula (Eq. 1) as a variable in three-dimensional regression plot of $S_{\mathrm{w}}, R_{\mathrm{w}} / R_{\mathrm{t}}$ and $\phi$. The 3D technique determines Archie's parameters $a, m$ and $n$ by solving three simultaneous equations for $S_{\mathrm{w}}, R_{\mathrm{w}} / R_{\mathrm{t}}$ and porosity Eq. 1 is rearranged after taking the logarithm of both sides.

$\log R_{\mathrm{w}} / R_{\mathrm{t}}=-\log a+m \log \phi+n \log S_{\mathrm{W}}$

The left hand side of Eq. 5 is a dependent variable of the two independent variables $S_{\mathrm{w}}$ and $\phi$. Equation 5 is an equation of a plane in 3D space of coordinate $x, y$ and $z\left[x=\log \phi, y=\log S_{\mathrm{w}}\right.$ and $\left.z=\log R_{\mathrm{w}} / R_{\mathrm{t}}\right)$. The intersection of this plane with the plane $(x=0.0$ gives a straight line of slope $m$, with the plane $(y=0.0)$ giving a straight line with slope $n$ and with the plane $(z=0.0)$ ] providing the value of a parameter.

For a given set of data for a core sample, an equivalent set of variables $x, y$ and $z$ can be obtained, Eq. 5 will take the following form for $i$ measurement points:

$Z_{i}=-A+m X_{i}+n Y_{i}$

After normalizing Eq. 6 for $N$ reading, we can have the following three simultaneous equations:

$\Sigma Z_{i}=-N A+m \Sigma X_{i}+n \Sigma Y_{\mathrm{i}}$

$\Sigma X_{i} Z_{i}=-A N \Sigma X_{i}+m \Sigma X_{i} 2+n \Sigma X_{i} Y_{i}$

$\Sigma Y_{i} Z_{i}=-A N \Sigma Y_{i}+m \Sigma X_{i} Y_{\mathrm{i}}+n \Sigma Y_{i} 2$

The solution of Eqs. 7-9 provides the values of Archie's parameters $a, m$ and $n$ for one core sample. For $j$ core samples, running the same analysis for $j$ core samples produces an average value of Archie's parameters.

Assumptions. First, 3D technique assumes that Archie formula is applicable to the examined core samples. Also, the core samples represent the zone of interest for shaly sandstone, Archie formula must be modified to account for the presence of shale and its effect on resistivity measurements. The user is free to select the appropriate shaly sand water saturation equation. The second assumption might be difficult to satisfy, as it deals with the accuracy of the laboratory measurements under 
Table 1 Archie's parameters values from four techniques

\begin{tabular}{llll}
\hline Method & $a$ & $m$ & $n$ \\
\hline Conventional method & 1.12 & 1.87 & 2.04 \\
CAPE $(1, m, n)$ method & 1.00 & 1.52 & 1.92 \\
CAPE $(a, m, n)$ method & 0.23 & 2.15 & 2.87 \\
3D method & 0.28 & 2.34 & 2.12 \\
\hline
\end{tabular}

Table 2 Error analysis of Archie's parameters determination techniques

\begin{tabular}{|c|c|c|c|c|c|c|}
\hline \multirow[t]{2}{*}{ Methods } & \multicolumn{3}{|c|}{ Absolute error } & \multirow[t]{2}{*}{$E_{\mathrm{rms}}$} & \multirow[t]{2}{*}{$S$} & \multirow[t]{2}{*}{$R$} \\
\hline & $E_{\mathrm{a}}$ & $E_{\min }$ & $E_{\max }$ & & & \\
\hline Conventional method & 0.206 & 0.004 & 1.09 & 0.31 & 0.23 & 0.90 \\
\hline CAPE $(1, m, n)$ method & 0.125 & 0.001 & 0.38 & 0.16 & 0.10 & 0.90 \\
\hline CAPE $(a, m, n)$ method & 0.095 & 0.001 & 0.33 & 0.12 & 0.08 & 0.92 \\
\hline 3D method & 0.102 & 0.002 & 0.51 & 0.14 & 0.10 & 0.91 \\
\hline
\end{tabular}

reservoir conditions The third assumption deals with the concept of the 3D technique; this means that the user must be acquainted with the basis and limitations of each method before using it.

\section{Field application and statistical analysis}

The conventional, CAPE, and 3D techniques were applied to field examples of carbonate reservoir rock. Table 1 shows typical results from the conventional method, the CAPE method, and the 3D method. Note that for CAPE method, cases where $(a)$ is fixed at unity and other variable are given as an input to the equation. In addition to $m$, $n$ and values, the five error parameters were used to evaluate techniques regarding to water saturation. These five error parameters are given in Table 2 (the absolute error, the minimum and maximum absolute error, the correlation coefficient, standard deviation and finally the root mean square relative error). Figures 6 and 7 show the average
Fig. 6 The average error, RMS error and standard deviation between the four techniques
Fig. 7 The $R$-squared values for the different techniques
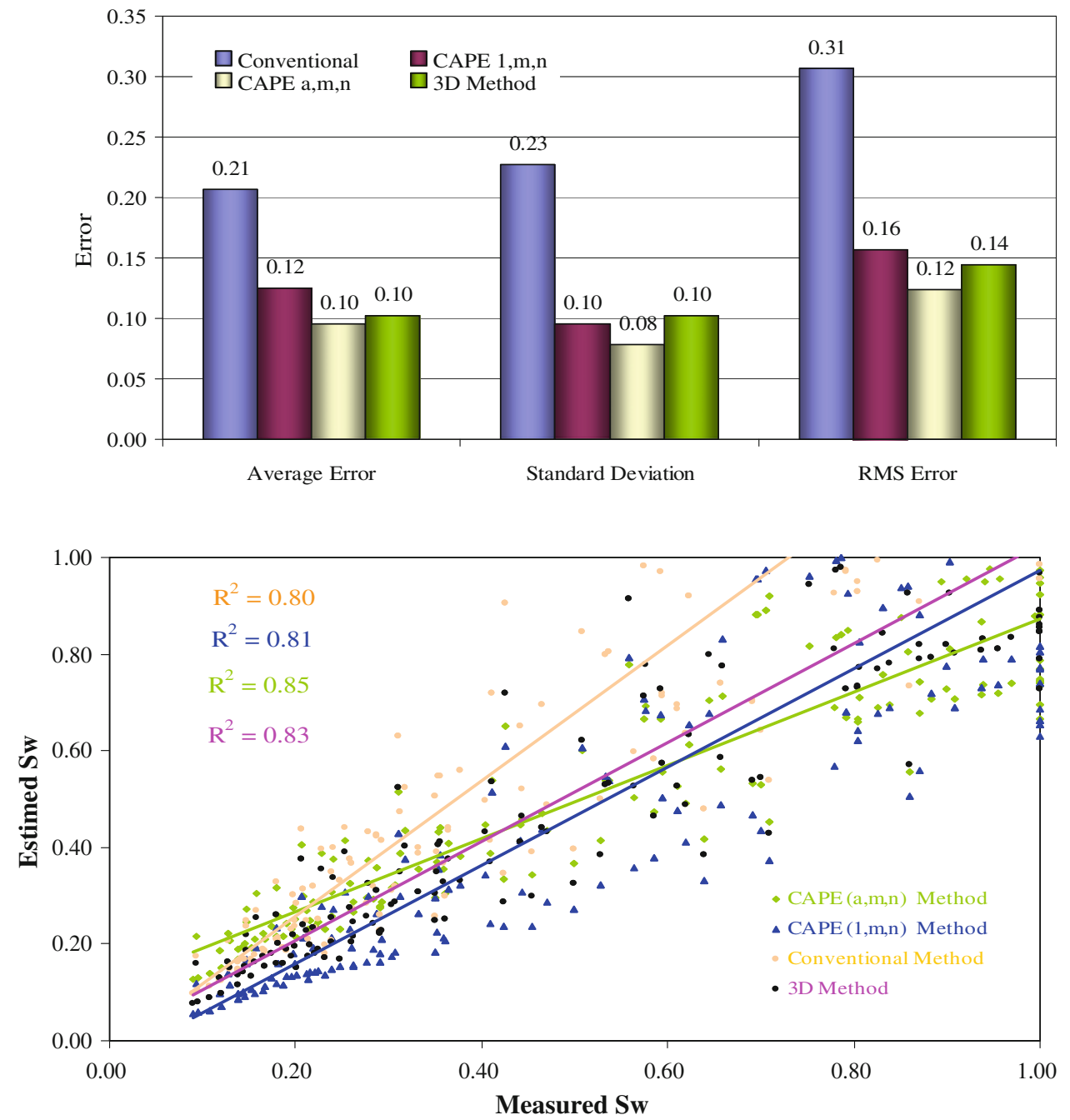
error, the root mean square error, standard deviation, and finally the $R$-square error and to highlight the accuracy of different techniques.

It is to note that the values of $a, m$ and $n$ deduced by the four methods are different. In addition, note that the saturation root mean square, average error and standard deviation decrease as we go as the following methods are used: (1) conventional methods to (2) CAPE method with parameter (a) equals to one, (3) 3D method, and (4) CAPE with, $a$, variable. This performance was expected and it could be attributed to the fact that conventional method tries to optimize the two functions $F$ versus $\phi$, and $R_{\mathrm{t}}$ versus $S_{\mathrm{w}}$ rather than water saturation, while CAPE, and 3D optimize water saturation. Although the CAPE types have the lowest root mean square error, but the 3D method is still more credited compared to CAPE by less computer time-consuming and by its optimization technique which is more physically concerned with water saturation and related factors than the CAPE method. Therefore, it is recommended to use the $3 \mathrm{D}$ or CAPE (with, $a$, variable) technique to get an accurate values of $a, m$ and $n$ required for water saturation equation.


Fig. 8 a Comparison between measured with calculated water saturation from four techniques, and $\mathbf{b}$ relative error between four techniques 
Variable Archie's parameters and water saturation values

Laboratory measured saturation exponent (n) showed some variations from standard value of 2 depending on the rock type. An exact value of saturation exponent is necessary for a good log interpretation analysis to a precise water saturation determination. There are many factors affecting saturation exponent, such as rock wettability, grain pattern, the presence of certain authigenic clays, particularly chainosite, which may promote oil wet characteristics and history of fluid displacement. However, it is found that rock wettability is the main factor affecting saturation exponent $(n)$. Archie's saturation equation makes three implicit assumptions (1) the saturationresistivity relation is unique, (2) $n$ is constant for a given porous medium and (3) all brine contributes in the electric current flow. It is found that these assumptions are valid only in water wet reservoir. This is because saturation exponent $n$ depends on the distribution of the conducting phase in the porous medium and, therefore, depends on the wettability saturation exponent $(n)$, which is about 2 in water-wet rock, where brines spread over grain surface and facilitate the flow of electric current, it may reach 25 in strongly oil-wet rock, where oil coats the grain surface and causes disconnections and isolation of globules of brine and, therefore, this will not be able to conduct a current flow.

Figure 8a illustrates typical results of measured and determined water saturation profiles for different Archie's parameters deduced from conventional method, CAPE, and 3D method. Figure $8 \mathrm{~b}$ depicts water saturation relative error profiles calculated by the four options against selected interval for core samples. The examination of water saturation profiles has shown that (1) the use of conventional values yields water saturation values greater than the correct ones, and that (2) unlike the case of conventional values, the water saturation profiles calculated by CAPE with, a, variable and 3D methods did not show certain departure from each other. For application, where highest possible accuracy in water saturation is desired, it is recommended to leave the conventional method and adopt any of the CAPE or the 3D methods. In addition, the CAPE and $3 \mathrm{D}$ method is more preferred, because it is more physically representative of the data and it overcomes the dilemma of whether $(a)$ is to be fixed at unity or not. Figure $8 \mathrm{a}, \mathrm{b}$ shows clearly the measured and estimated water saturation profile calculated by different methods. These profiles support the accuracy analysis to study the performance of different techniques to obtain the most accurate techniques. Note that the water saturation has a good matching when we used the CAPE $(a, m, n)$ method with $(a)$ variable and the $3 \mathrm{D}$ method.

\section{Conclusions}

1. CAPE and 3D methods provide the minimum uncertainty and thus they are a strong alternative to conventional method for estimating Archie' parameters from core data.

2. Conventional technique is currently in use, but it has serious limitations on the determination of parameters, $a$ and $m$, separately from saturation exponent $n$. This is physically not correct.

3. CAPE technique is based on the minimum error between measured water saturation and calculated water saturation values.

4. The 3D technique is based on the simultaneous solution of three variables of Archie's formula ( $a, m$ and $n$ ).

5. Comparison of calculated water saturation values (using Archie's parameters from the three techniques) with cores water saturation values has shown that CAPE and 3D techniques are more accurate than conventional technique.

6. Error analysis showed that conventional technique has a higher error level than the CAPE and 3D techniques.

Acknowledgments The authors would like to thank the research institute, KFUPM, for running the experiments part of the research and for supporting the work, and also UAE University for permitting publishing this paper.

Open Access This article is distributed under the terms of the Creative Commons Attribution License which permits any use, distribution, and reproduction in any medium, provided the original author(s) and the source are credited.

\section{References}

Al-Ruwaiili SB, Alwaheed HH (2004) Improved petrophysical methods and techniques for shaly sands evaluation. In: SPE\# 89735 presented at SPE Annual Technical Conference, Houston, Texas, USA, 26-29 Nov 2004

Archie GE (1942) The electrical resistivity $\log$ as an aid in determining some reservoir characteristics. Trans AIME 146:54-62

Atkins ER, Smits GH (1961) The significance of particle shape in formation resistively factor-porosity relationship. JPT 3:285-291

Bori AM (1987) A new correlation for the cementation factor in lowporosity carbonates. SPE Form Eval 495-498

Chilingarian GV, Torbazadeh J, Metghalchi M, Rieke HH, Mazzullo SJ (1992) Interrelationships among surface area, permeability, porosity, pore size and residual water saturation, carbonate reservoir characterization: a geologic engineering analysis part 1 . Elsevier Publ. Co., Amsterdam, 30, pp 379-397

Clavier C, Coates G, Demanoir J (1984) Theoretical and experimental bases for dual water model for interpretation of shaly sands. JPT 24(2):153-168

Dernaika MR, Efnik MS, Koronful MS, Mansoori M, Hafez H, Kalam MZ (2007) Case study for representative water saturation from laboratory to logs and the effect of pore geometry on capillarity. 
In: SCA \# 2007-38 presented at SCA International symposium, Calgary, Canada, 10-12 Sept 2007

DeWhite L (1950) Relation between resistivities and fluid contents of porous rocks. Oil Gas J 49:120-132

Serag El S, Dernaika MR, AlHasani I, Skjaeveland (2010) Whole core versus plugs: integrating log and core data to decrease uncertainity in petrophysical interpretation and STOIP calculations, SPE 137679. The Abu Dhabi Intl Petroleum Exhibition and Conference, Abu Dhabi, 1-4 Nov 2010

Fluery M (1998) FRIM: a fast resistivity index measurement method. In: Proceedings of the SCA-9829 Intl. Symposium of the Society of Core Analysts, Amsterdam, 15-17 Sept 1998

Hamada GM, Al-Awad MN, Al-Sughayer AA (2002) Water saturation computation from laboratory, 3-D regression. Oil Gas Technol Rev IFP 57(6):637-651

Hamid SG, Saadat K, Kazemzadeh E (2011) A case study of saturation exponent measurement of some carbonate cores at full reservoir conditions, SCA2011-42

Han M, Fluery M, Levitz P (2007) Effect of the pore structure on resistivity index curves. In: SCA 2007-34 Intl. Symposium of the Society of Core Analysts, Aberdeen, 15-17 June 2007

Jodry RI (1992) Pore geometry of carbonate and capillary pressure curves (basic geologic concepts), carbonate reservoir characterization: a geologic engineering analysis part 1: Elsevier Publ. Co., Amsterdam, 30, pp 331-377

Kennedy WD, Herrick DC, Yao T (2001) Calculating water saturation in electrically anisotropic media. Petrophysics 42(2):118-136

Maute RE, Lyle WD, Sprunt E (1992) Improved data-analysis method determines Archie parameters from core data. JPT 103-107

Morgan WB, Pirson SJ (1964) The effect of fractional wettability on the Archie saturation exponent. In: Paper B presented at 5th SPLWAL Annual Technical Conférence, Midlands, USA, 13-15 May 1964

Sen PN (1997) Resistivity of partially saturated carbonate rocks with microporosity. Geophysics 62(2):456-465

Simandoux P (1963) Measures diélectriques on milieu poreux, application a measure des saturations en eau, étude du comportement des massifs argileux Revue de L'IFP, pp 193-215

Wardlaw NC (1996) Factors affecting oil recovery from carbonate reservoirs and prediction of recovery, carbonate reservoir characterization: a geologic engineering analysis part II: Elsevier Publ. Co., Amsterdam, 30, pp 867-903

Waxman MH, Smits LJM (1968) Electrical conductivities in oilbearing shaly sands. JPT 8:107-122

Worthington PF (2011) The petrophysics of problematic reservoirs. JPT 12:88-97 